\title{
Evaluation of consequences of the potential accidents in the Norwegian coastal waters
}

\author{
M. Iosjpe, O. Reistad and I. Amundsen \\ Norwegian Radiation Protection Authority, PO Box 55, 1332 Østerås, Norway
}

\begin{abstract}
Potential accidents with modern operative nuclear submarine and with transport of spent nuclear fuel along the Norwegian coastal line have been under evaluation. Hypothetical release scenarios which include immediate discharge of release fraction and constant release of fuel corrosion products, were developed. Modelling work has been done using a compartment model developed at NRPA which includes the dispersion of radioactivity in marine regions, processes of water-sediment interactions and dose assessment modules. Collective dose-rates to man, concentration of radionuclides in biota/sea-foods and doses to marine organisms were calculated. Results from the calculation of concentrations of radionuclides in marine organisms as well as doses to man and biota are discussed.
\end{abstract}

\section{INTRODUCTION}

The evaluation of radioecological consequences after the potential accidents in this paper corresponds to two scenarios: accident with a modern operative nuclear submarine and accident with a transport of spent nuclear fuel along the Norwegian coastal line.

\subsection{Submarine}

Since the inception of its naval nuclear program, the Soviet Union/Russia has built a total of 255 nuclearpropelled surface and submersible military vessels. Most of these have been fitted with two reactors. Today's Russian fleet consists of some 37 vessels stationed in the Russian High North and Far East. Two-thirds of these are third-generation vessels. Numerous accidents have occurred as a result of this activity, and there are genuine concerns for large-scale releases that may come as a result of Russian activities involving marine reactors. This study is a response to the lack of updated assessments that take into account the increased nominal reactor power and the latest results from studies on reactor and fuel design and operational parameters $[1,2]$. The objective has been to establish an upper threshold for the potential impact on the marine environment in the case of a Russian submarine accident involving a modern vessel with a maximum credible inventory of radionuclides and maximum release.

\subsection{Ship transport}

Several types of radioactive materials are, and regularly have been, by sea during the nuclear era, such as uranium ores, radioisotopes, nuclear fuel assemblies, spent nuclear fuel (SNF) and radioactive waste. Such shipments have caused controversy and attracted public attention, especially among coastal states along the chosen marine transport routes. For example, in 2002 the Russian Federation supplemented the Federation Law "Concerning use of atomic energy" from 1995 with an article opening the possibility of importing foreign SNF to Russia [3] as a commercial enterprise. This has lead to concern in Norway centred on the safety and security of SNF and other radioactive material shipments, the responsibility and/or liability of transport states and potential impacts on the marine environment in the event of an accident at sea. Reductions in the extent and thickness of polar sea ice increases the duration during 
which Arctic waters are navigable [4] and the Northern Russian sea route constitutes the shortest sea route between Asia and the nuclear fuel reprocessing centres of Western Europe.

\section{METHODOLOGY}

\subsection{Source terms}

The source terms, which describes the release of radioactive materials from a specific source, has in this work been consolidated to inventory, release as a function of time and a release point. The energy content is negligible as the accident scenario in question is taking place under water and there is free exchange of water between the spent fuel and sea. The inventory has been developed using the HELIOS programme in the case of submarine and the ORIGEN [5] programme in the case of ship transport on the basis of core data given below. The release as a function of time has been established on the basis of the worst-case assessment, taking the fuel, reactor and other containment properties into account as discussed below.

\subsubsection{Submarine}

According to [6], evaluation of the core inventory in the current work is based on assumption that the most probable representation of a Russian third-generation submarine core is a core load with $63 \%$ enriched fuel with $259,7 \mathrm{~kg}$ U-235 in a dispersion $\left(\mathrm{UO}_{2}-\mathrm{Al} / \mathrm{UO}_{2}-\mathrm{Zr}\right)$ or intermetallic configuration $\left(\mathrm{UAl}_{\mathrm{x}}-\mathrm{Al}\right)$. Average annual burn-up has been calculated to 30 effective full-power days (EFPD) and the maximum operational period hypothetically set to 20 years. At present, the average life-span for this class of vessels is 13.2 years. As the current decommissioning rate is higher than the commissioning rate, we may assume that this value will decrease slowly in the future. However, as the selection criterion has been a maximum credible burn-up, and normal vessel life is more than 13.2 years, we may assume 20 years of operation as a conservative estimate as a basis for calculating the radionuclide inventory at the time of the accident. The resultant burn-up is $114,000 \mathrm{MWd}$, or $269,000 \mathrm{MWd} /$ ton of heavy metal (HM). It has also assumed an operating power fraction of 0.5 at the time of accident, resulting in a high inventory of short-lived isotopes when the hypothetical accident occurs.

It is necessary to note that the main methodological problem concerning the release fractions is the lack of relevant information on fuel materials, subsequently, on radionuclide behavior in fuel matrixes under extreme conditions (high temperature, saltwater intrusion etc.). However, a nuclear system with potentially similar attributes to those of third-generation reactors (high power densities, high enrichment levels and moderate burn-up levels) is found in civilian research reactors. The hypothetical correspondence in fuel design and fuel properties has formed the basis for assessments of fuel consumption [6]. The present release scenario includes immediate discharge of release fraction (core-melt release) and constant release of fuel corrosion products with corrosion rate $0,01 \%$ of fuel material annually (fuel corrosion) [6].

\subsubsection{Ship transport}

For the potential accidents, a standard fuel assembly has been chosen, using relatively low enrichment, 3,2\%, and two different burn-up values (standard 38 169/extended $53068 \mathrm{MWd} / \mathrm{tHM}$ ), with average cooling times as 5 years. This was chosen on the basis of that future transport along the Norwegian coast probably will happen with fuel from reactors designed recently, therefore lower enrichments and higher burn-up values are particular relevant.

The source term has been divided into two terms: an instantaneous release of radionuclides, often referred to as the instant release fraction and a slow long-term contribution corresponding to the dissolution of the uranium oxide matrix. It was chosen a conservative approach with of $10 \%$ release 
of the total inventory immediately after the sinking of the ship with following annual release of $0,09 \%$ of the inventory over the course of 1000 years.

The total available release inventory of radioactivity for a standard fuel assembly, at the time of the ship sinking, was assumed to be 30,1 PBq [5]. Two scenarios with transport of 10 and 100 assemblies were considered. For the worst case scenario, which is presented here, the source term inventory was assumed to be 100 spent fuel assemblies with a release pattern divided into two fractions: an instantaneous release of radionuclides (instant release fraction) and a slow long-term release to model the dissolution of the uranium oxide matrix. It is necessary to note that the present scenario is more conservative than the release scenario, which was used in [7], where the total inventory was assumed to be $1290 \mathrm{PBq}$. However, understanding the potential impacts of a serious accident during marine transport of SNF along the Arctic coastline is of interest when considering the magnitude of possible effects and worst-case scenario for coastal populations in affected areas and for the environment in general.

\subsubsection{Accident location}

The geographical location of the accident with nuclear submarine, with subsequent release, has been set to the marine region outside the Russo-Norwegian border areas in the Barents Sea close to the operating naval bases in Northwest Russia, while the geographical location of the ship transport accident was chosen with the greatest possible affect on the Norwegian Coastal Waters in mind. Accident locations are shown in Figure 1.

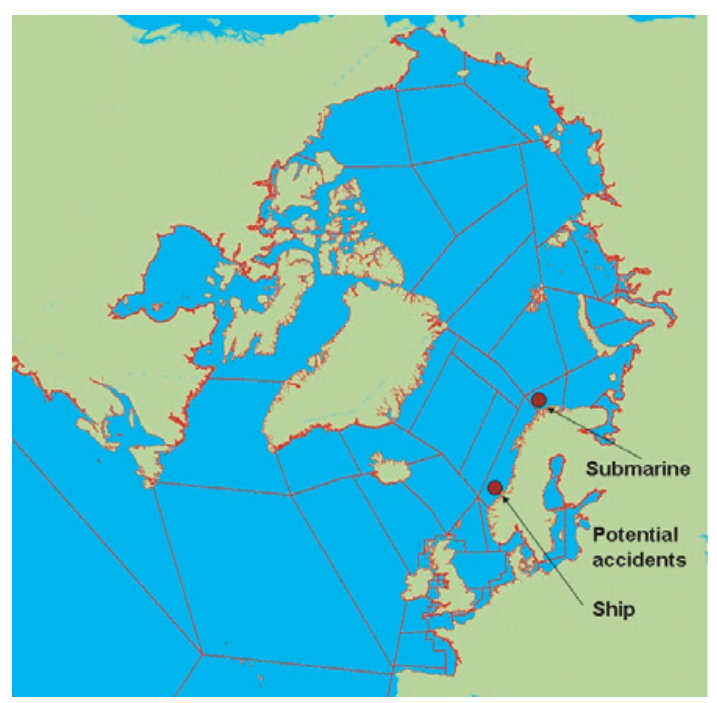

Figure 1. Potential accident locations.

\subsection{Model description}

The box model developed in NRPA uses the modified approach for compartmental modelling which includes dispersion of radionuclides during time (non-instantaneous mixing in oceanic space) [8]. The model includes the processes of advection of radioactivity between compartments, sedimentation, diffusivity of radioactivity through the pore water, resuspension, mixing due to bioturbation and particle mixing and a burial process of activity in deep sediment. The contamination of biota is further calculated from the radionuclide concentrations in filtered seawater in the different water regions. Doses to man 
are calculated on the basis of data for the catch of seafood and assumptions about human diet. Doses to biota are calculated on the basis of radionuclide concentrations in marine organisms, water and sediment and dose conversion factors $[8,9]$.

\section{RESULTS AND DISCUSSION}

Evaluation of radioecological consequences is provided on the basis of calculations collective dose rates to man, concentrations of radionuclides in biota with regards to seafood and doses to marine organisms.

Results of calculations of collective dose rates for global population for both present accident scenarios show that maximum dose rate occur during the second year after is released. Results of calculations for submarine accident are shown in Figure 2. Figure 2 presents also results for the radionuclides that were calculated to have the most significant impact regarding doses to man during the initial period of release.

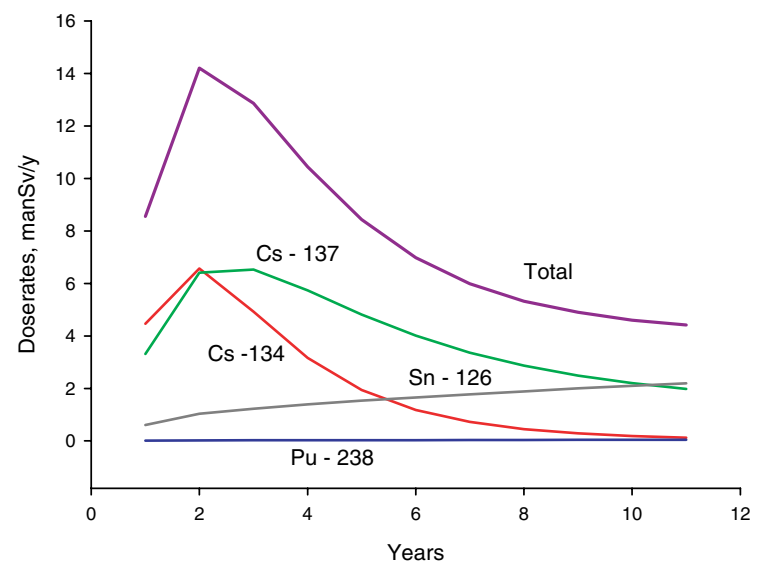

Figure 2. The total collective dose-rate for world population and the individual contributions from selected radionuclides calculated for the initial period following the accident with nuclear submarine.

The maximum collective dose rate is approximately 14 manSv per year, with ${ }^{137} \mathrm{Cs}$ and ${ }^{134} \mathrm{Cs}$ giving the highest impact on total collective dose rates. Dynamic of collective dose rate calculated for accident with ship transport of SNF shows similar behaviour with maximum collective dose rate of $200 \mathrm{manSv}$, approximately. Radionuclides ${ }^{137} \mathrm{Cs}$ and ${ }^{238} \mathrm{Pu}$ result in the most significant impact to the total dose rate.

The calculated concentrations of radionuclides in marine biota (fish, molluscs and crustaceans) were evaluated with regards to recommendations of the Food Standards Programme [10]. According to [10] radionuclides can be separated into four groups. Examples of some typical radionuclides for each group are presented in Table 1. The model calculations indicated that concentrations of radionuclides in marine biota remain below the levels recommended by [10]. However, calculated concentrations of radionuclides in marine biota for radionuclides in group 3 and 4 (for submarine accident scenario) and for radionuclides in group 1 and 2 (for ship transport accident scenario) were, in some cases, higher than the recommended levels. Figure 3 likewise indicates that concentrations of radionuclides in molluscs were higher than guideline levels during the first four years after the accidental releases began and were above guidelines for infant foods for more than ten years. The most significant impact on concentration levels for group 1 radionuclides was observed for ${ }^{238} \mathrm{Pu}$.

Dose rates calculated for the different marine organisms (fish, crustacean and mollusc) were compared with screening dose rate $10 \mu \mathrm{Gy} / \mathrm{hr}$, which has previously been suggested as not harmful to marine biota [11]. Results of dose rate calculations indicate that maximal doses to biota from the studied 


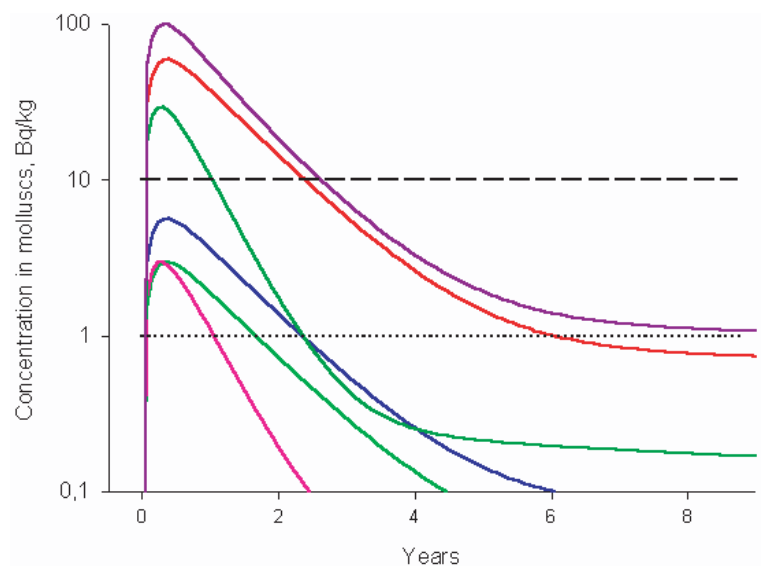

Figure 3. Comparison of radionuclide concentrations calculated in molluscs with recommended levels provided by [10] in radionuclides in Group 1. Dotted and dashed lines correspond to recommended levels of radionuclides for infant food and other food, respectably.

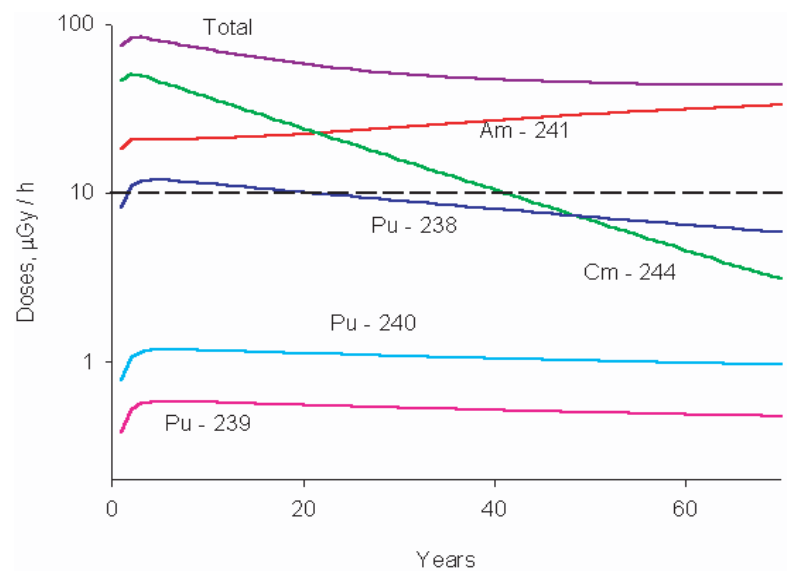

Figure 4. Calculated dose rates for the Polychaete worm under the accident scenario under ship transport of radionuclides. The screening dose of $10 \mu \mathrm{Gy} / \mathrm{hr}$ is indicated.

Table 1. Examples of international recommendations levels for radionuclides in food [10].

\begin{tabular}{|l|l|l|l|}
\hline Example radionuclides & & \multicolumn{2}{|l|}{ CAC guideline levels (Bq/kg) } \\
\cline { 3 - 4 } & & Infant foods & Other foods \\
\hline Group 1 & ${ }^{238} \mathrm{Pu},{ }^{239} \mathrm{Pu},{ }^{241} \mathrm{Am}$ & 1 & 10 \\
\hline Group 2 & ${ }^{90} \mathrm{Sr},{ }^{106} \mathrm{Ru},{ }^{129} \mathrm{I}$ & 100 & 100 \\
\hline Group 3 & ${ }^{60} \mathrm{Co},{ }^{134} \mathrm{Cs},{ }^{137} \mathrm{Cs}$ & 1000 & 1000 \\
\hline Group 4 & ${ }^{3} \mathrm{H},{ }^{14} \mathrm{C},{ }^{99} \mathrm{Tc}$ & 1000 & 10000 \\
\hline
\end{tabular}

accident scenarios were generally below this level. However, under special circumstances, calculations indicated that dose rates could exceed $10 \mu \mathrm{Gy} / \mathrm{hr}$ for the studied scenarios. For example, Figure 4 shows the dose rate for the polychaete worm exceeded the screening dose rate $(10 \mu \mathrm{Gy} / \mathrm{hr})$ by up to one order of magnitude during a time period that would affect many generations of this particular marine organism (Figure 4 has constructed according to scenario with ship transport of radionuclides). This result can be 
explained by the polychaete worm's habitat, as it lives in sediments that can have higher concentrations of certain radionuclides in comparison to other marine organisms in the water.

Results of calculations show that, in spite of the very conservative scenarios, the collective dose rates to man are not high in comparison with similar doses from natural causes. However, elevated dose rates and concentration of radionuclides in marine biota for some particular cases indicate that monitoring of affected areas would require special considerations for different types of marine organisms. Following improvement of the present knowledge about the processes of bioaccumulation and water-sediment interactions we can significantly increase the precision of dose assessment.

\section{References}

[1] O. Reistad, M. Mærli and N. Bøhmer, The Nonproliferation Review 12 (2005), 163-197.

[2] O. Reistad, R. Stamm'ler and K. Gussgard, Science and Global Security, submitted for publication February 4, 2008.

[3] The Russian federal law concerning bringing of the supplement into federal law "Use of Atomic Energy" (in Russian), http://www.akdi.ru/gd/proekt/088017GD.SHTM (2002).

[4] IPCC, (1996), Climate Change 1995: Impacts, Adaptations, and Mitigation of Climate Change: Scientific-Technical Analyses. Contribution of Working Group II to the Second Assessment Report for the Intergovernmental Panel on Climate Change [Watson, R.T., M.C. Zinyowera and R.H. Moss (eds.)]. Cambridge University Press, Cambridge, United Kingdom and New York, NY, USA.

[5] T.L. Sanders, K.D. Seager, Y.R. Rashid, P.R. Barrett, A.P. Malinauskas, R.E. Einziger, H. Jordan and X. Duffey, A method for determining the spent-fuel contribution to transport cask containment requirements. SAND 90-2406. Albuquerque: Sandia National Laboratories (1992).

[6] O. Reistad, M. Iosjpe, W. and S. Hustveit, Source term development and impact assessment of a hypothetical accident for a Russian nuclear submarine in the Barents Sea (2008). Provisional draft.

[7] Severity, probability and risk of accidents during maritime transport of radioactive material, Final report of a coordinated research project 1995-99, IAEA-TECDOC-1231, Vienna: International Atomic Energy Agency, 2001.

[8] M. Iosjpe, J. Brown and P. Strand, J. Environ. Radioactivity, 60, 91-103 (2002).

[9] M. Iosjpe, in Radionuclides in the Environment. edited by P.P. Povinec and J.A. Sanchez-Cabeza (Radioactivity in the Environment, 8, Series Editor: M.S. Baxter, 463-476, (2006).

[10] Codex Alimentarius Commission: Joint FAO/WHO Food Standards Programme. Appendix XXXI. ftp://ftp.fao.org/codex/Alinorm06/al29_41e.pdf (09.01.07)

[11] J.E. Brown, A. Hosseini, P. Børretzen and H. Thørring, Marinne Pollution Bulletin, 52, 1127-1137 (2006). 